\title{
Magnetically Geared Induction Machines
}

\author{
S. Mezani ${ }^{1,2}$, T. Hamiti ${ }^{1}$, L. Belguerras ${ }^{1}$, T. Lubin ${ }^{2}$, M. Rashed $^{1}$ and C. Gerada ${ }^{1}$ \\ ${ }^{1}$ The University of Nottingham, Faculty of Engineering, PEMC group, Nottingham, NG7 2RD, UK \\ ${ }^{2}$ Université de Lorraine, FST, Laboratoire GREEN, Vandœuvre-lès-Nancy, 54506, France
}

\begin{abstract}
A wound rotor induction machine is artfully coupled to a magnetic gear to achieve a high torque density drive system called MaGIM "Magnetically Geared Induction Machine". The high-speed rotor of MaGIM is common to both the machine and gear sides. A rotating diode rectifier electrically links the machine's wound rotor and a dc 'boost' winding on the gear side to increase the torque transmission capabilities of the overall system. The first investigations on a $100 \mathrm{~kW}-120 \mathrm{rpm}$ MaGIM are promising since a torque increase of about $15 \%$ could be obtained by inserting the diode rectifier. For fixed speed applications, this induction-machine-based system can be directly supplied from the mains.
\end{abstract}

Index Terms - Magnetic gears, Induction machines, Wound rotor

\section{INTRODUCTION}

$I^{1}$ N LOW speed/high torque applications, a compact system is achieved using a mechanical gear to match a high speed/low torque machine to its load. This requires lubrication, cooling and maintenance and results in potential jamming at overload operation. Direct drive solutions are of limited torque density in achieving low speed/high torque output because of limited admissible heating factor.

In the last decade, a new concept of magnetically geared Permanent Magnet (PM) machines has been introduced for a wide variety of applications [1]-[4]. In such a system, the transmitted torque is limited by the magnetic gear transmission capability, based only on the interaction between magnets through field-modulating ferromagnetic pieces.

We aim here to introduce a novel topology using an induction machine/magnetic gear to achieve a high torque/low speed drive system with extended torque transmission capabilities. This concept is called magnetically geared induction machine (MaGIM).

\section{PRINCIPLE OF OPERATION OF MAGIM}

Figure 1 presents a schematic view of the MaGIM device. It is composed of four armatures among which two are stationary and the two others are rotating at different speeds. The principle of operation of MaGIM is described hereafter:

1- The most inner armature represents the stator of the induction machine. A p pole-pair, 3-phase winding is located in the slots. When supplied via a balanced 3-phase voltages (or currents), a rotating magnetic field is created in the machine air gap.

2- This rotating field induces currents in another $\mathrm{p}$ pole-pair, 3phase winding which faces the stator. This results in an electromagnetic torque production which moves the high-speed rotor at a mechanical speed $\Omega_{\mathrm{h}}$.

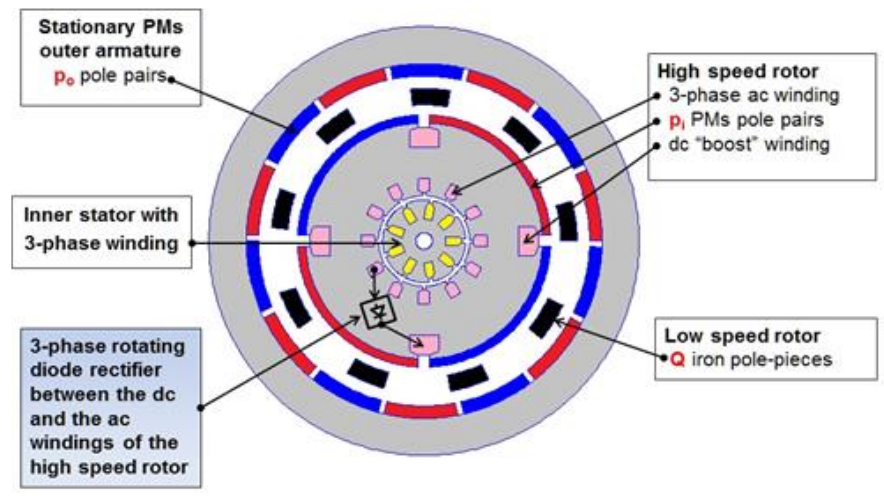

Fig. 1. 2D cross section view of MaGIM

3- The magnetic gear is mounted on the external surface of this high speed rotor. The principle of operation of the magnetic gear is based on modulating the magnetic field created by $\mathrm{p}_{\mathrm{i}} \mathrm{PM}$ pole-pairs by $\mathrm{Q}$ ferromagnetic pole pieces. The obtained field interacts with $p_{o} \mathrm{PM}$ pole-pairs of the external armature to transmit torque to the low-speed load. The combination $\mathrm{p}_{\mathrm{o}}=\mathrm{Q}-$ $\mathrm{p}_{\mathrm{i}}$ results in the highest torque transmission capability of the gear. The external armature being held stationary, the torque is transmitted to the low-speed load via the pole-pieces. The resulting gear ratio is then $\mathrm{Gr}=\mathrm{Q} / \mathrm{p}_{\mathrm{i}}$ so the speed of the polepieces (low-speed rotor) is $\Omega=\Omega_{\mathrm{h}} / \mathrm{Gr}$.

Notice that the overall torque on the high-speed rotor is null, as the machine torque cancels the high-speed torque of the gear. In such a system, the transmitted torque is limited by the interaction between magnets via the pole-pieces.

In order to increase the torque transmission capabilities of the system, 3-phase windings on the high-speed rotor are electrically connected to a pi pole-pairs dc winding (called dc boost winding) via a rotating diode rectifier. This results in an extra torque which allows more operation flexibility compared to magnetically geared PM machines.

The description of the principle of operation of MaGIM presented here doesn't address the full theory behind each component of the studied system. The main objective of the paper is to show the effectiveness of the proposed device in 
achieving a high torque density drive system with extra torque rise. Nevertheless, relevant works on magnetic gears and magnetically geared PM machine [1]-[4], [9] as well as on induction machines [5], [8] can help the reader understand this theory.

\section{APPLICATION EXAMPLE}

A MaGIM rated at $100 \mathrm{~kW}, \Omega=115-120 \mathrm{rpm}, 8000 \mathrm{Nm}$ is considered for the simulation studies. It is supplied from the mains at $400 \mathrm{~V}-50 \mathrm{~Hz}$, so a constant speed application is considered here.

\section{A. Preliminary design of MaGIM}

As it can be seen, the MaGIM design is a complex task. There are many electromagnetic interactions between the different armatures which makes it difficult to have a simple sizing procedure like in conventional electrical machines. For a preliminary design, the machine and the gear sides are considered separately.

First, the machine has been sized using the electrical and magnetic loading concept together with past experience from machine manufacturers [5]-[6]. A large number of physical and geometrical design parameters arises ( 20). Constrained multiobjective Genetic Algorithms (GA) optimization has been used to deal with the preliminary design. The computations are carried out thanks to the NSGA2 Matlab implementation of GA [7]. The objective functions are to maximize the efficiency and to minimize the machine active volume. The most important constraints concern the minimal value of the power factor, the limitation of the saturation level and the heating factor. As reported in [8], the heating factor is the product of the electric loading and the current density. It allows a predetermination of the convection coefficient needed for sizing the cooling system. In our study, it has been set to a maximum value of 2000 $\left(\mathrm{A}^{2} / \mathrm{mm}^{2} . \mathrm{cm}\right)$ which results in medium values of the convection coefficient (typically around $100 \mathrm{~W} / \mathrm{m}^{2} . \mathrm{K}$ ).

Then, the gear design is considered (without the boost winding). An analytical model based on the formal resolution of Maxwell's equations [9] is used. Again, constrained multiobjective Genetic Algorithms optimization was used to deal with the preliminary design. The objectives are the minimization of the PMs weight and the total gear volume (which also corresponds to the total active volume of MaGIM).

Many simulations are needed to achieve a good compromise between the optimal performances of the machine and the gear sides. In the final stage, finite element analyses are carried out to consider the overall system in which we need to accommodate the boost winding. The FE refinement is done manually but it doesn't take a long time since the GA preliminary design already gives a good starting configuration. We have used "MAGNET" software from INFOLYTICA to perform the FE computations.

Fig. 2 presents the optimal Pareto fronts obtained for the designed MaGIM. The optimization time is very short for the machine side $(\sim 2 \mathrm{~min})$ but much longer for the gear side $(\sim 2$ hours). The optimal parameters for the final design are those given in Table I obtained with 2D finite element computations. The ferromagnetic parts are made from Silicon iron laminations (grade EN 10106, $0.5 \mathrm{~mm}$ thickness). The main performances of the deigned MaGIM are given in Table II.

Fig. 3 shows the flux lines and the flux density distribution in the studied device. It can be seen that the flux density norm is limited to $1.4 \mathrm{~T}$ in most of the iron parts. Notice that the narrowing of the yoke in the vicinity of the slots for the boost winding could have a negative impact on the performance of MaGIM, so this has to be considered carefully in the design process.

Fig. 4 presents the dynamic torque at rated speed on the high speed rotor. This torque comes from the machine and the gear sides, which cancel each other. Indeed, the high-speed rotor doesn't drive any load so its total net torque is zero.

TABLE I

Main parameters of the $100 \mathrm{~kW}$ MaGIM

\begin{tabular}{|c|c|}
\hline Parameter description & Value \\
\hline \multicolumn{2}{|l|}{ Machine side } \\
\hline Stator rated voltage, Vs & $400 \mathrm{~V}(\Delta$ connection $)$ \\
\hline Stator frequency & $50 \mathrm{~Hz}$ \\
\hline Pole pairs, $\mathrm{p}$ & 3 \\
\hline Number of stator slots, Ns & $72(10 / 12$ shortening $)$ \\
\hline Number of rotor slots, $\mathrm{Nr}$ & $54(7 / 9$ shortening, Y) \\
\hline Stator outer radius & $201.4 \mathrm{~mm}$ \\
\hline Air gap & $0.6 \mathrm{~mm}$ \\
\hline Active length & $260 \mathrm{~mm}$ \\
\hline Stator slot height & $49 \mathrm{~mm}$ \\
\hline Stator tooth width (rectangular) & $8.6 \mathrm{~mm}$ \\
\hline Stator back-iron height & $42 \mathrm{~mm}$ \\
\hline Rotor slot height & $32 \mathrm{~mm}$ \\
\hline Rotor tooth width (rectangular) & $10.9 \mathrm{~mm}$ \\
\hline Rotor back-iron height & $50 \mathrm{~mm}$ \\
\hline Turns per phase (stator and rotor) & 72 \\
\hline Stator (Rotor) per phase resistance & $85 \mathrm{~m} \Omega(78 \mathrm{~m} \Omega)$ \\
\hline Stator (Rotor) phase leakage inductance & $3.1 \mathrm{mH}(2.9 \mathrm{mH})$ \\
\hline Magnetizing inductance & $55 \mathrm{mH}$ \\
\hline \multicolumn{2}{|l|}{ Gear side } \\
\hline Inner rotor pole-pairs, $\mathrm{p}_{\mathrm{i}}$ & 5 \\
\hline Stationary armature pole-pairs, $\mathrm{p}_{\mathrm{o}}$ & 36 \\
\hline Number of pole-pieces, Q & 41 \\
\hline Gear ratio, $\mathrm{Gr}$ & 8.2 \\
\hline Airgap (inner and outer rotor sides) & $2.5 \mathrm{~mm}$ \\
\hline Inner rotor PMs thickness & $7 \mathrm{~mm}$ \\
\hline Stationary armature PMs thickness & $5 \mathrm{~mm}$ \\
\hline Pole-pieces thickness & $18 \mathrm{~mm}$ \\
\hline Remanence of PMs & $1.3 \mathrm{~T}$ \\
\hline Inner rotor radius & $307 \mathrm{~mm}$ \\
\hline External radius & $350 \mathrm{~mm}$ \\
\hline Boost winding slot area & $4.8 \mathrm{~cm}^{2}$ \\
\hline Resistance (per turn) of the boost winding, $\mathrm{R}_{\mathrm{b}}$ & $0.2 \mathrm{~m} \Omega$ \\
\hline Inductance (per turn) of the boost winding, $\mathrm{L}_{\mathrm{b}}$ & $60 \mu \mathrm{H}$ \\
\hline
\end{tabular}

TABLE II

Main performances of the $100 \mathrm{~kW}$ MaGIM at rated operation

\begin{tabular}{ll}
\hline \hline Quantity & Value \\
\hline Stator phase current & $109 \mathrm{~A}(\mathrm{rms})$ \\
Rotor phase current & $101 \mathrm{~A}(\mathrm{rms})$ \\
Speed of inner rotor (high speed), $\Omega_{\mathrm{h}}$ & $975 \mathrm{rpm}$ \\
Slip, s & $2.5 \%$ \\
Speed of outer rotor (low speed), $\Omega$ & $119 \mathrm{rpm}$ \\
Torque exerted on outer rotor & $7970 \mathrm{Nm}$ \\
Power factor & 0.83 \\
Efficiency & 0.93 \\
Iron losses & $500 \mathrm{~W}$
\end{tabular}


It can be seen that the gear side torque is almost ripple-free (it is also the case for the low-speed rotor) but the machine torque exhibits some ripples which are mainly due to the slotting effects.

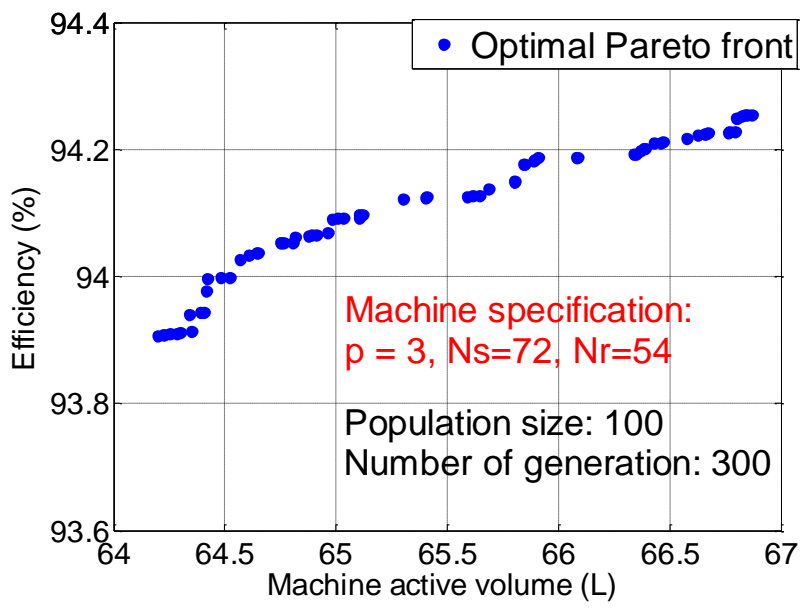

(a)

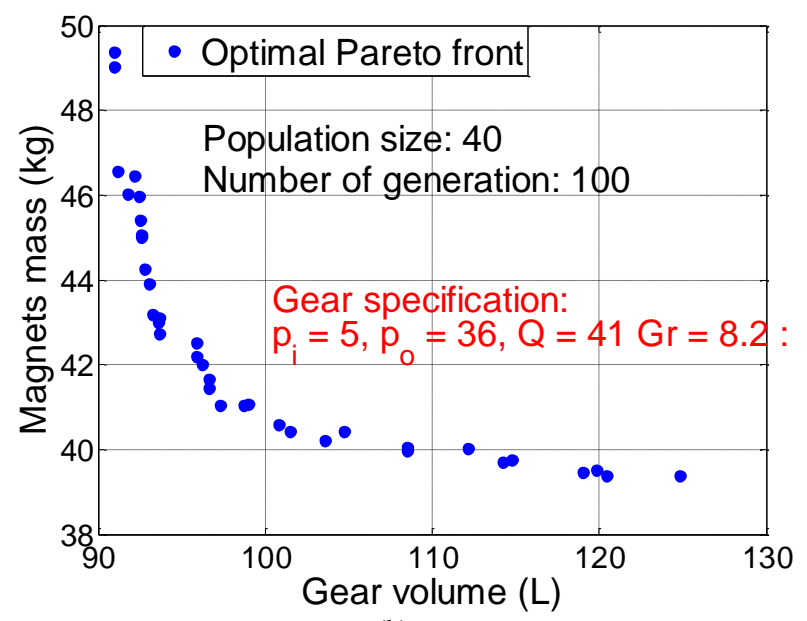

(b)

Fig. 2. Optimal Pareto fronts: (a) Efficiency vs. machine active volume, (b) PMs mass vs. gear volume

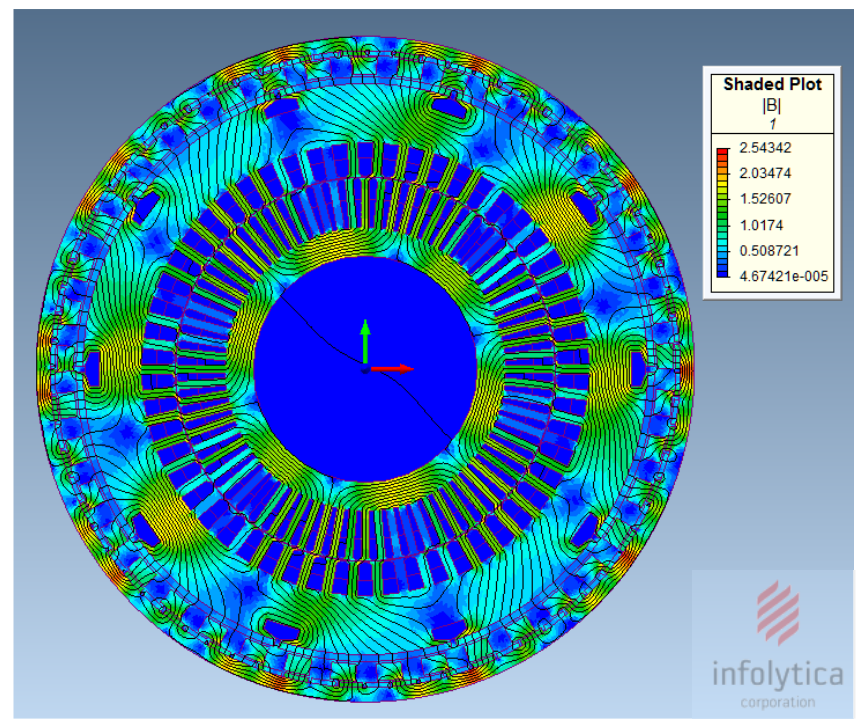

Fig. 3. Flux lines and flux density distribution at rated operation (boost winding is disconnected)

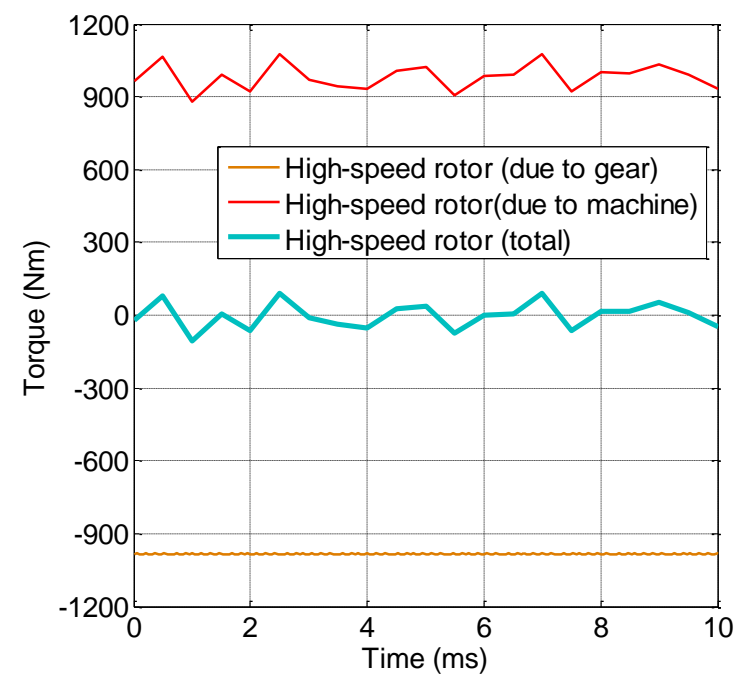

Fig. 4. Torque exerted on the high-speed rotor at rated operation (boost winding is disconnected)

\section{B. Introduction of the boost winding}

In order to study MaGIM when the boost winding is connected, a circuit-based model has been developed under Matlab/Simulink - Simscape SimPowerSystems. A dq model is used for the machine. The wound rotor terminals are connected to the ac side of the 3-phase diode rectifier whose dc side is connected to the boost winding (represented by its R, L parameters). Notice that a forward voltage of $0.5 \mathrm{~V}$ and an internal resistance of $1 \mathrm{~m} \Omega$ are assumed for the diodes.

The boost winding resistance and inductance are those given in Table I $\left(\mathrm{R}_{\mathrm{b}}, \mathrm{L}_{\mathrm{b}}\right)$ for 1 turn per slot. For Ndc turns per slot, the boost winding resistance and inductance become $\mathrm{Rdc}=\mathrm{Ndc}^{2} \times \mathrm{R}_{\mathrm{b}}$ and $\mathrm{Ldc}=\mathrm{Ndc}^{2} \times \mathrm{L}_{\mathrm{b}}$, respectively.

In the simulation studies, the torque developed by the machine is fixed to $970 \mathrm{Nm}$ (rated power at $120 \mathrm{rpm}$ ).

Figs. 5 presents the performances of MaGIM for Ndc values up to 10 .

In order to keep the torque at the desired value, the speed of the high-speed rotor decreases as Ndc increases, Fig. 5.a. The machine power also decreases which results in relatively constant current values in the stator and rotor windings.

The power factor and the efficiency (the boost winding losses are taken into account) also decrease but remain acceptable compared to the situation when the boost is disconnected (viz. $\mathrm{Ndc}=0$ ).

The interest of introducing the boost winding can be observed from Figs. 5. c and d. The dc current in the boost winding (Fig. 5.c) will create an extra torque (obviously, the load angle of the gear will vary with Idc to keep the torque at the desired value). The pull-out torque (computed by FE) referred to the low-speed rotor is shown in Fig.5.d. Compared to the situation where the 
boost is disconnected $(\mathrm{Ndc}=0)$, a torque increase of about $15 \%$ is obtained when $\mathrm{Ndc}=10$.

This constitutes a major advantage of MaGIM compared to PMs geared machine:

- There is no need to oversize the gear for overload operation

- MaGIM would probably have better transient performances with fast recovery from slipping [10].

\section{CONCLUSION}

A new concept of high torque density magnetically geared induction machine has been proposed. A continuous torque density in excess of $70 \mathrm{Nm} / \mathrm{L}$ and $78 \mathrm{Nm} / \mathrm{L}$ with the boost winding can be achieved.

MaGIM offers several advantages which stem from two features inherent to this concept. The first is that the boost winding results in an additional continuous torque production or a potential possibility of reducing the magnets volume. The second feature relates to transient performances including the probability of having a better recovery from slipping.

Further works are ongoing to consider the boost winding in the optimization procedure of the MaGIM system. Thermal modeling is also to be considered in the design process in order to define the cooling requirements. The behavior of MaGIM within a vector-controlled drive system is also being investigated.

Of course, it will also be necessary to build a prototype for a full validation of the MaGIM concept.

\section{ACKNOWLEDGMENT}

This work is carried out under an EU Marie-Curie IEF fellowship - Project MaGIM, No PIEF-GA-2012-330833.

\section{REFERENCES}

[1] A. Penzkofer, and K. Atallah, "Magnetic Gears for High Torque Applications," IEEE Trans. Magn., vol. 50, 8104104, Nov. 2014.

[2] Y. Liu, S. Niu, S. L. Ho, and W. N. Fu, "A New Hybrid-Excited Electric Continuous Variable Transmission System," IEEE Trans. Magn., vol. 50, 8104704, Nov. 2014.

[3] E. Morimoto, K. Hirata, N. Niguchi, and Y. Ohno, "Design and analysis of magnetic-geared motor with field windings," IEEE Trans. Magn., vol. 50, 8204204, Nov. 2014.

[4] K. Atallah, J. Rens, S. Mezani, and D. Howe, "A no vel 'pseudo' directdrive brushless permanent magnet machine," IEEE Trans. Magn., vol. 44, no. 11, pp. 4349-4352, Nov. 2008.

[5] I. Boldea, and S. A. Nasar, The Induction Machines Design Handbook, 2nd ed., CRC Press, 2009, 845 p.

[6] Y. Duan, and R. G. Harley, "A no vel method for multi-objective design and optimization of three phase induction machines," ECCE Conference, Atlanta, USA, 12-16 Sept. 2010, pp. 284-291.

[7] S. Lin, NGPM - A NSGA-II Program in Matlab v1.4, Available online: http://uk.mathworks.com/matlabcentral/fileexchange/31166-ngpm-ansga-ii-program-in-matlab-v1-4

[8] M. Kostenko and L. Piotrovsky, Electrical machines, $3^{\text {rd }}$ ed., Mir Publisher, 1974.

[9] T. Lubin, S. Mezani, and A. Rezzoug, "Analytical computation of the magnetic field distribution in a magnetic gear," IEEE Trans. Magn., vol. 46, no. 7, pp. 2611-2621, Jul. 2010.

[10] M. Bouheraoua, J. Wang and K. Atallah, "Slip recovery and prevention in pseudo direct drive permanent magnet machines," IEEE Trans. on Ind. Appl., (early access article), 2014.

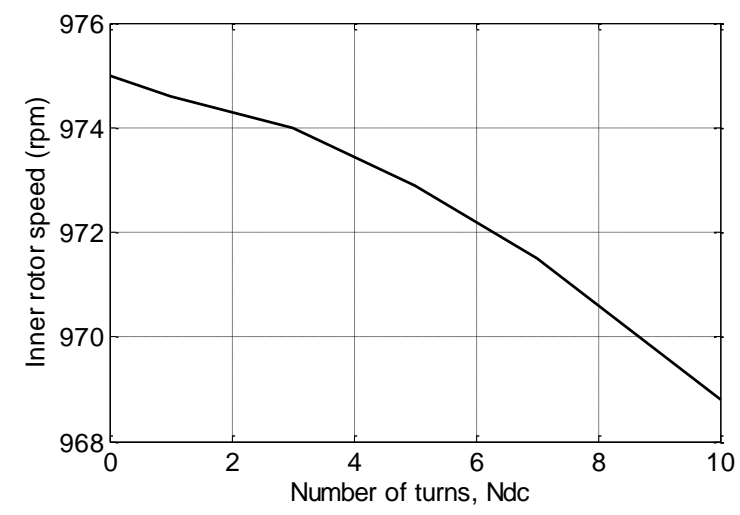

(a)

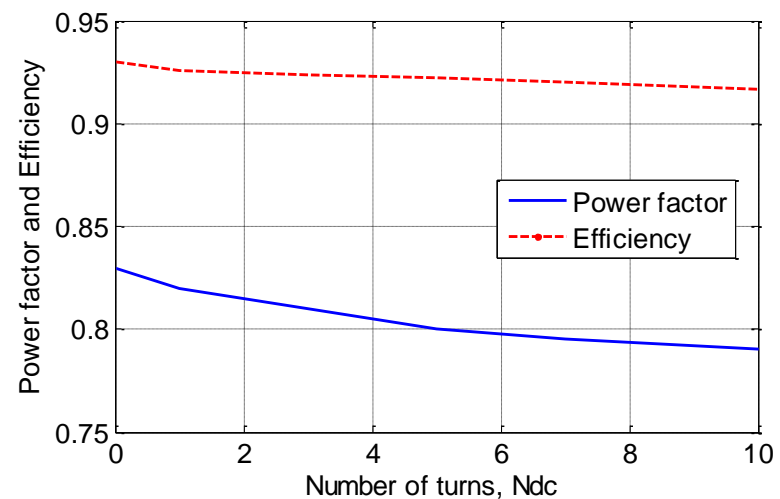

(b)

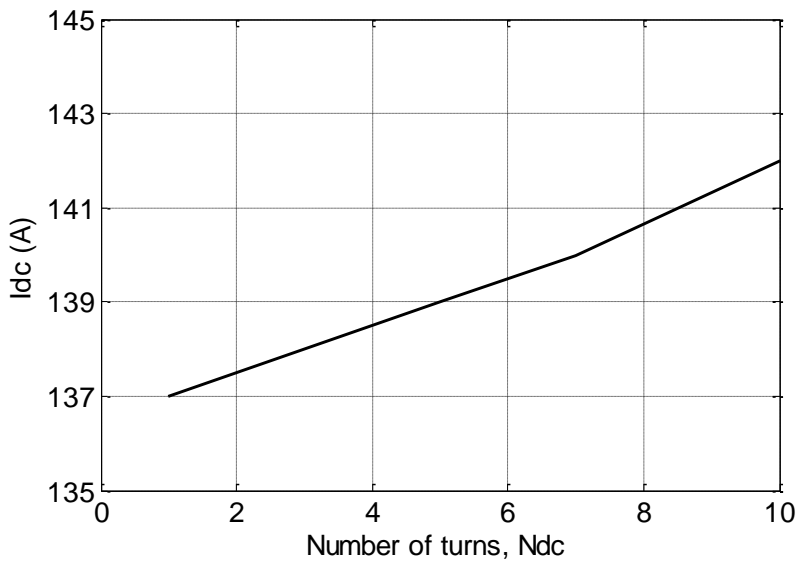

(c)

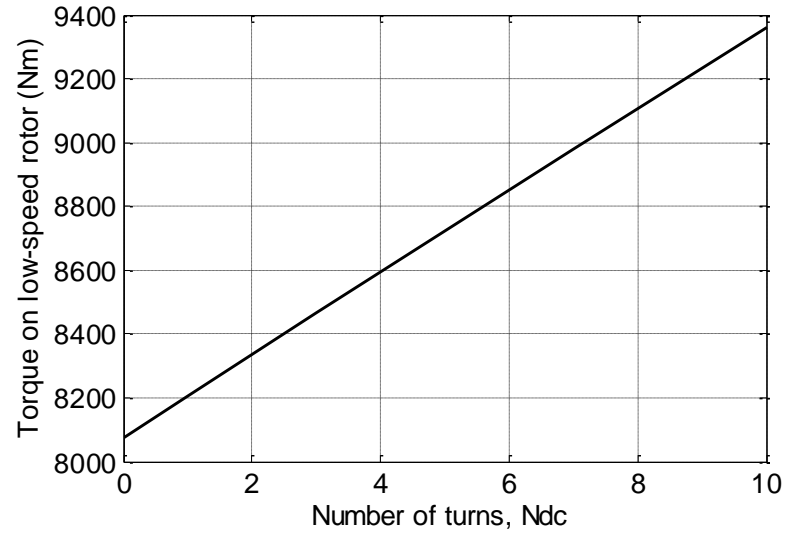

(d)

Fig. 5. Influence of Ndc on MaGIM performances: (a) Speed of the highspeed rotor (b) Power factor and Efficiency (c) dc current of the boost winding, (d) Pull-out torque on the low-speed rotor 